\title{
Eine neue Varietät von Pentodon punctatus Vill.
}

Von Guido Depoli, Fiume.

In den Reitterschen Bestimmungstabellen der europäischen Lamellicornier (II. Heft, pag. 18) wird unter den übrigen Merkmalen für Pentodon punctatus Vill. aufgeführt, daß die „Vorderschienen zwischen dem zweiten und dritten inneren Zahne mit deutlichem Zähnchen" versehen sind; in der Fauna germanica desselben Autors (II. Bd., pag. 340) wird dies wiederholt.

Zwischen den in der nächsten Umgebung der Stadt Fiume gesammelten $P$. punctatus fand ich nun ein Exemplar, welchem dieses Zähnchen fehlte; bei näherer Untersuchung konnte ich noch andere Abweichungen, durch welche ich diese Form von den übrigen Stücken meiner Sammlung, welche der typischen Beschreibung entsprachen, gut auseinanderhalten konnte, feststellen. Ich hätte aber, bei der allen Scarabaeiden eigenen großen Neigung zur Variation, diesen Fall nur als individuelle Abweichung betrachtet, wenn ein mir aus Sizilien (von Prof. Co n iglio-Fanales in Caltagirone) zugekommenes Exemplar nicht dieselben Eigenschaften aufgewiesen hätte. So halte ich es aber für angezeigt, diese Form als Varietät mit einem Namen zu belegen und sie folgendermaßen zu beschreiben.

Pentodon punctatus Vill. nov. var. simplex.

Vorderschienen zwischen dem zweiten und dritten inneren Zahne scharf eingekerbt, ohne Spur eines Zähnchens. Der Sporn auf der Innenseite steht dieser Einkerbung gegenüber. Borstenkranz der Hinterschienen aus kurzen, in unregelmäfigen Abständen aufragenden, gleichlangen Borsten bestehend; nur die den Enddornen am nächsten stehenden sind etwas länger. Hinterschenkel auf der Unterseite, ein Drittel seiner Länge von der Basis entfernt, mit einem seichten, schrägen Eindruck. Halsschild mit einer punktfreien Mittellinie, welche breiter und kürzer (sie reicht von hinten bis zur Hälfte des Halsschildes) als bei der Stammform ist; auf den Seiten gegen vorn mit je einer kleinen, nicht gut begrenzten, ebenfalls punktfreien Fläche. Unterseite heller braun gefärbt als die Stammform.

Nach der großen Entfernung der zwei mir bekannten Standorte $\mathrm{zu}$ urteilen, handelt es sich nicht um eine Lokalform und dürfte var. simplex mit der Stammform zusammen, wie es eben in Fiume der Fall ist, vorkommen. Sie wurde bis jetzt wahrscheinlich übersehen, was um so erklärlicher ist, als $P$. punctatus Vill. sein Verbreitungsgebiet mit keiner nahe verwandten Form gemein hat und so auch ohne eingehendere Untersuchung sofort erkannt werden kann. 


\section{$2 \mathrm{BHL}$ Biodiversity Heritage Library}

Depoli, Guido. 1910. "Eine neue Varietät von Pentodon punctatus VILL." Wiener entomologische Zeitung 29, 306. https://doi.org/10.5962/bhl.part.23366.

View This Item Online: https://www.biodiversitylibrary.org/item/44117

DOI: https://doi.org/10.5962/bhl.part.23366

Permalink: https://www.biodiversitylibrary.org/partpdf/23366

\section{Holding Institution}

Smithsonian Libraries

\section{Sponsored by}

Smithsonian

\section{Copyright \& Reuse}

Copyright Status: NOT_IN_COPYRIGHT

This document was created from content at the Biodiversity Heritage Library, the world's largest open access digital library for biodiversity literature and archives. Visit BHL at https://www.biodiversitylibrary.org. 